\title{
Assessment of Timing of First Antenatal Care Visit and Associated Factors Among Pregnant Women Attending Antenatal Care in Dilla Town Governmental Health Institutions, Southern Ethiopia
}

\section{Tadele Girum ${ }^{*}$}

Department of Public Health, Arba Minch College of Health Sciences, Arba Minch, Ethiopia

"Corresponding author: Girum T, Department of Public Health, Arba Minch College of Health Sciences, Arba Minch, Ethiopia. Tel: +251913652268; E-mail: girumtadele@yahoo.com

Received date: August 22, 2016; Accepted date: September 03, 2016; Published date: September 08, 2016

Copyright: @ 2016 Girum T. This is an open-access article distributed under the terms of the Creative Commons Attribution License, which permits unrestricted use, distribution, and reproduction in any medium, provided the original author and source are credited.

\begin{abstract}
Introduction: The new focused antenatal care model recognizes that every pregnant woman is at risk for complications and four antenatal care visits are recommended for most pregnant women; the first one being early in the first trimester. When pregnant women attend antenatal care late they miss the cares being provided in the first 16 weeks. Therefore it is important to assess timing of first antenatal care visit and identify associated factors for late coming for the sake of intervention.

Methods: Institutional based cross-sectional study was conducted among 362 randomly selected pregnant women from April to June 2014 in Dilla town, Southern Ethiopia. The data had been entered in to Epi Info version 7 and analyzed through SPSS version 20. Bivariate analysis was run to look for the association between dependent and explanatory variables; and using variables which have $p$-value $\leq 0.25$ binary logistic regressions was fitted. Association presented in odds ratio with $95 \%$ confidence interval and significance determined at $P$-value less than 0.05 .

Results: The mean time of first antenatal care visit was found to be 15.9 (SD 3.7) weeks and the proportion of women who visit their first antenatal care within the recommended time (before or at 16 weeks of gestation) was $49.7 \%$; nearly equal to late presentation. Rural residence $(\mathrm{AOR}=3.6,95 \% \mathrm{Cl}(1.72,6.62)$ ), low monthly income $(A O R=3.20,95 \% \mathrm{Cl}(1.5,6.74))$, illiteracy $(A O R=1.48,95 \% \mathrm{Cl}(1.12,3.04))$, not being advised on timing of visit $(\mathrm{AOR}=4.64,95 \% \mathrm{Cl}(2.32,8.17)$ and unplanned pregnancy $(\mathrm{AOR}=5.02,95 \% \mathrm{Cl}(2.21,8.95))$ were independent predictors of late presentation for first antenatal care.
\end{abstract}

Conclusion: Even though, half of pregnant women started antenatal care attendance during the first trimester the finding was not satisfactory. Hence, further activities are needed through health education and promotion.

Keywords: Antenatal care; Timing; First antenatal care booking

\section{Introduction}

Globally, more than half a million women are still dying annually as a result of complications of pregnancy and childbirth [1]. Ninety-nine percent of these occur in developing countries, of these deaths $50 \%$ occurred in Sub-Saharan Africa (SSA) [2]. Thus a woman in Africa may face a lifetime risk of death during pregnancy and childbirth as high as one in 26 , compared with only one in 7300 in developed regions [3]. Ethiopia is one of the countries with the highest maternal mortality, with 420 mother's death per 100,000 live birth and much more morbidities were there [4]. With the appropriate care, maternal mortality is in fact a very rare event. The care provided at pregnancy, delivery and postpartum periods markedly reduce maternal mortality [1-3].

Pregnancy is a very important event from both social and medical points of view. Therefore, pregnant women should receive special care and attention from the family, community and from the health care system. The objective of antenatal care (ANC) is to assure that every pregnancy culminates in the delivery of a healthy baby without impairing the health of the mother [5] which includes prevention, identification and treatment of conditions as well as help a woman approach pregnancy and birth as a positive experiences through health promotion and disease prevention, early detection and treatment of complications and existing diseases, birth preparedness and complication readiness planning programs.

World health organization (WHO) recommends that, pregnant women should seek ANC within the first three months of pregnancy. Early antenatal care attendance during the first three months of gestation plays a major role in detecting and treating some complications of pregnancy and forms a good basis for appropriate management during delivery and after childbirth. Failure to attend antenatal care early results in the potential for complications during pregnancy, delivery and puerperium [6,7]. However, existing evidence from developing countries including Ethiopia indicates that few women seek antenatal care at early stage of their pregnancy $[8,9]$.

Studies have identified several factors that influence the utilization of antenatal care in developing countries, although there are few studies regarding factors affecting the timing of first ANC attendance. These factors include, among others, maternal education, and 
Citation: Girum T (2016) Assessment of Timing of First Antenatal Care Visit and Associated Factors Among Pregnant Women Attending Antenatal Care in Dilla Town Governmental Health Institutions, Southern Ethiopia. Altern Integr Med 5: 220. doi: $10.4172 / 2327-5162.1000220$

Page 2 of 5

husband's education, availability of health service, cost, household income, women's employment, media exposure, and having a history of obstetric complications [10-12].

Therefore, timely ANC is generally acknowledged to be an effective method of preventing adverse outcomes of pregnancy. Thus this study aimed to assess timing of first antenatal care visit and associated factors among pregnant women attending ANC clinics in Dilla town governmental health institutions, 2014.

\section{Materials and Methods}

\section{Study design and settings}

This cross-sectional study was conducted from April 01 to June 30, 2014 at public health facilities of Dilla town, Southern Ethiopia. The town has a total population of 96,920 of which 47,394 are males \& the rest 49,526 are females organized in three sub cities. There are two public health centers and one referral hospital which offer ANC service and other maternal health packages.

\section{Study population and sampling technique}

The study population was pregnant women who attended ANC service in Dilla town public health institutions. The sample size was calculated using single population proportion formula $\mathrm{n}=(\mathrm{Z} \text { a/2 })^{2} \mathrm{P}$ $(1-\mathrm{P}) / \mathrm{d}^{2}$ based on the following assumptions: proportion of timely ANC visit is taken $31 \%$ from [8], significant level at $\alpha=0.05$, at $95 \%$ confidence interval, margin of error is $5 \%$ and $10 \%$ nonresponse rate, the minimum sample size became 362 pregnant women. The sample was allocated proportionally for the three health facilities and collected with a systematic random sampling technique. Annual performance report of the health institutions the year before the study period was taken as reference to estimate the client load in each health institution. Based on the information proportion to sample for each institution under the study was allocated. Therefore, $63 \%$ (228) of the sample size was allocated to hospital and the rest to health centers. Systematic random sampling technique was used and every second pregnant mother was selected for an exit interview. The first study subject was determined randomly.

All pregnant women who were attending antenatal care service in Dilla town that came to health institution during data collection period were eligible for the interview and pregnant women who were unable to hear and speak were excluded.

\section{Data collection procedure and data quality control}

The data collection tool was first prepared in English after reviewing related literatures and then translated to Amharic language. Exit interview technique was used to collect data with structured and pretested questionnaire. Data were collected by four midwives after trained for a day and supervised by the principal investigator. The check list sought information on: socio-demographic characteristics, obstetric history, past experiences and physical findings. The data were collected by three nurses after getting training.

\section{Study variables and data analysis}

The dependent variables is timing of first ANC which is dichotomized as late initiation (after 16 week of gestation) which is coded zero and other wise as early; and the independent variables were characteristics, obstetric history, past experiences and physical findings. After data collection, each questionnaire was checked for completeness and consistency. Data was cleaned, coded and entered into Epi-info version 7 and exported to SPSS version 20 for Windows, then exploratory data analysis carried out to check the levels of missing values, presence of influential outliers, independence of errors, multicollinearity and normality.

Binary and multiple logistic regressions were run to assess the association of various factors with late presentation. Variables significant at $\mathrm{P}<0.25$ level in the bivariate analysis were included in the final binary logistic regression analysis, to identify independent predictors. The forward stepwise regression method was applied to get a list of best predictors and any statistical test is considered significant at $\mathrm{P}$ level less than 0.05 in the final model. Covariates were checked for interaction effect. Finally the fitness of the model was checked by Hosmer and Lemeshow test. The results were presented in the form of tables, texts and figure. The strength of association of predictor variables were assessed using odds ratio and significance of variables were reported by using $95 \%$ confidence interval and $p$-values $<0.05$.

\section{Ethical statement}

Ethical clearance was obtained from institutional review office of Arba Minch University. Permission to conduct the study also was obtained from town administration selected institutes. Informed consent was obtained from each study participants. Each respondents were informed about the purpose of the study and also that all data obtained from them were kept confidential by using codes instead of any personal identifiers.

\section{Result}

\section{Socio-demographic characteristics of study participants}

Over all 362 pregnant women who were attending antenatal care service at public health facilities were interviewed and none of them have refused to respond for the interview. The respondents' age ranged from 16 to 36 years with a mean age of 25.46 (SD 6 years). More than half of the respondents were in the age group 25-34 years and 170 (47\%) were attended grade 12 and above in their educational level. The majority $158(43.6 \%)$ of women were private workers and all were married (Table 1).

\begin{tabular}{|l|l|}
\hline Characteristics & $\mathbf{N}(\%)$ \\
\hline Residence & \\
\hline Rural & $75(20.7)$ \\
\hline Urban & $287(79.3)$ \\
\hline Age & \\
\hline $15-24$ & $149(41)$ \\
\hline $25-34$ & $170(47)$ \\
\hline 35 and above & $43(12)$ \\
\hline Educational status & \\
\hline No formal school & $73(20)$ \\
\hline Primary & $107(29.6)$ \\
\hline Secondary & $103(28.5)$ \\
\hline
\end{tabular}


Citation: Girum T (2016) Assessment of Timing of First Antenatal Care Visit and Associated Factors Among Pregnant Women Attending Antenatal Care in Dilla Town Governmental Health Institutions, Southern Ethiopia. Altern Integr Med 5: 220. doi: $10.4172 / 2327-5162.1000220$

Page 3 of 5

\begin{tabular}{|l|l|}
\hline Grade $12+$ & $79(21.9)$ \\
\hline Monthly income & \\
\hline$<1000$ ETB & $175(48.3)$ \\
\hline$\geq 1000$ ETB & $187(51.7)$ \\
\hline Occupational status & \\
\hline Government employer & $108(29.8)$ \\
\hline Private/NGO & $158(43.6)$ \\
\hline No job & $88(24.3)$ \\
\hline Other & $8(2.2)$ \\
\hline
\end{tabular}

Table1: Socio demographic characteristics of the pregnant women in Dilla town public health facilities, South Ethiopia, 2014.

\section{Obstetric history and current pregnancy}

Majority of the respondents (71.4\%) were multiparas and among the pregnant women who ever gave birth, most of them (58.9\%) have gave birth to one child. The mean gestational age of the pregnant women during the interview time was 15.9 (SD 3.7) weeks. Majorities (47\%) had one and more ANC visits at the time of data collection. Among those respondents, having more than one pregnancy $80.3 \%$ had antenatal follow up in their previous pregnancies. Among those who are currently pregnant $74.86 \%$ was planned. Majority of them $63.8 \%$ knows their pregnancy after missing period while the rest by urine test. Of those who are currently pregnant $18 \%$ of them faced pregnancy associated complication (Table 2).

\begin{tabular}{|l|l|l|}
\hline Characteristics & & $\mathbf{N}(\%)$ \\
\hline History of still birth (321) & Yes & $8(2.5)$ \\
\hline History of abortion (321) & Yes & $65(20.2)$ \\
\hline Last pregnancy complication (321) & Yes & $208(64.8)$ \\
\hline ANC visit for last pregnancy (321) & Yes & $229(71.3)$ \\
\hline have advised on ANC (362) & Yes & $259(71.55)$ \\
\hline pregnancy planned (362) & Yes & $271(74.9)$ \\
\hline check for pregnancy (362) & Missed period & $231(63.8)$ \\
\hline pregnancy related medical complication & Yes & $65(18)$ \\
\hline
\end{tabular}

Table 2: Obstetrics and current pregnancy related response among pregnant women in Dilla town public health facilities, South Ethiopia, 2014.

\section{Timing of first ANC attendance}

Based on mothers recall and record, review the proportion of mothers who made their first ANC visit later than the 16 week; beyond the recommended time were 182 (50.3\%). Similarly equivalent proportion of mothers visited in the recommended time (within 16 weeks of gestation). Timing of first ANC attendance ranges from $4^{\text {th }}$ week to $36^{\text {th }}$ week during pregnancy; with mean gestational age of 15.9 (SD 3.7) weeks. Two hundred fifty nine (71.55) pregnant women were received advice about ANC use from any one before their first ANC visit, majorly from health extension workers and community voluntaries. In addition $83 \%$ of pregnant women were aware about danger signs during pregnancy; they mention one danger sign of pregnancy.

\section{Factors associated with late first antenatal care attendance}

The effects of each independent variable on the late initiation of first ANC were tested using binary logistic regression analysis. Among the variables place of residence, educational status, monthly household income, still birth, gravidity, advice status and pregnancy plan status were associated in bivariate analysis but others failed to show significant association.

The final multivariable model was built by using variables having Pvalues less than 0.25 in bivariate analysis with forward step wise method. After controlling the effect of other variables in the final multivariate model rural residence, no formal education, lower household income, not being advised and unplanned pregnancy were significantly associated with the outcome variable; late ANC booking for first visit.

Pregnant women who are living in rural areas were around four times $(\mathrm{AOR}=3.6,95 \% \mathrm{CI}(1.72,6.62))$ more likely to be late for first ANC attendance as compared to women of urban dwellers. The odds of pregnant women with monthly income of $<1000$ ETB to delay ANC booking were three times $(\mathrm{AOR}=3.20$, 95\% $\mathrm{CI}(1.5,6.74))$ higher compared to high monthly income family. Similarly the odds of late registration is $1.48(1.12,3.04)$ times higher for illiterates than literate mothers.

Pregnant women who was not advised the recommended time were $4.64(2.32,8.17)$ more likely to book late for their first ANC as compared to their counterparts who received advice on recommended time.

Pregnant women with unplanned pregnancy were five times ( $\mathrm{AOR}=5.02,95 \% \mathrm{CI}(2.21,8.95))$ more likely to book late for their first ANC as compared to their counterparts with planned pregnancy (Table 3).

\begin{tabular}{|c|c|c|c|c|}
\hline \multirow[t]{2}{*}{ Variables $(n=362)$} & \multicolumn{2}{|c|}{ First ANC attendance } & \multirow[t]{2}{*}{ Crude OR $(95 \% \mathrm{Cl})$} & \multirow[t]{2}{*}{ Adjusted OR $(95 \% \mathrm{Cl})$} \\
\hline & Late & Early & & \\
\hline \multicolumn{5}{|l|}{ Place of Residence } \\
\hline Rural & 60 & 15 & $5.4(3.2,7.5)$ & $3.6(1.72,6.62)^{*}$ \\
\hline Urban & 122 & 14 & 1 & 1 \\
\hline
\end{tabular}


Citation: Girum T (2016) Assessment of Timing of First Antenatal Care Visit and Associated Factors Among Pregnant Women Attending Antenatal Care in Dilla Town Governmental Health Institutions, Southern Ethiopia. Altern Integr Med 5: 220. doi: $10.4172 / 2327-5162.1000220$

Page 4 of 5

\begin{tabular}{|c|c|c|c|c|}
\hline \multicolumn{5}{|c|}{ Educational status } \\
\hline No formal educat. & 51 & 22 & $2.8(1.33,5.10)$ & $1.48(1.12,3.04)^{*}$ \\
\hline Formal education & 131 & 158 & 1 & 1 \\
\hline \multicolumn{5}{|c|}{ Occupational status } \\
\hline No job & 45 & 42 & $1.19(0.24-3.56)^{* *}$ & \\
\hline Have job & 130 & 145 & 1 & \\
\hline \multicolumn{5}{|l|}{ Monthly income } \\
\hline$<100$ ETB & 108 & 70 & $2.3(1.22,3.41)$ & $3.20(1.5,6.74)^{*}$ \\
\hline$\geq 1000$ ETB & 74 & 110 & 1 & 1 \\
\hline \multicolumn{5}{|l|}{ Gravida } \\
\hline One & 20 & 21 & $1.01(0.12,2.16)^{* *}$ & \\
\hline Two \& above & 156 & 165 & 1 & \\
\hline \multicolumn{5}{|l|}{ Advised } \\
\hline No & 72 & 31 & $3.14(1.93,5.78)$ & $4.64(2.32,8.17)^{*}$ \\
\hline Yes & 110 & 149 & 1 & 1 \\
\hline \multicolumn{5}{|l|}{ Plan of pregnancy } \\
\hline Un Planned & 64 & 27 & $3(1.8,4.32)$ & $5.02(2.21,8.95)^{*}$ \\
\hline Planned & 118 & 153 & 1 & 1 \\
\hline \multicolumn{5}{|c|}{ History of still birth } \\
\hline No & 5 & 3 & $1.68(1.05,9.45)^{* *}$ & $1.1(0.46,5.32)$ \\
\hline Yes & 176 & 178 & 1 & 1 \\
\hline
\end{tabular}

Table 3: Factors associated with timing of first ANC attendance among pregnant women in Dilla town public health facilities, South Ethiopia, 2014.

\section{Discussion}

This study assessed timing of first antenatal care visit and identified associated factors for late coming among pregnant women attending antenatal care in Dilla town public health institutions This study identified that the mean time to visit ANC for the first booking was 15.9 (SD 3.7) weeks and $50.3 \%$ of the pregnant women initiated antenatal care later than the recommended time (after 16 weeks). This finding is lower than studies conducted in Addis Ababa (Ethiopia), Western Kenya and South Western Nigeria in which the prevalence of late booking was $60 \%, 87 \%$ and $82.6 \%$ respectively [13-15]. This might be due to the time, socio-demographic, economic, and cultural differences as evidenced by our study was conducted after health promotion was advocated in the last two years and participants are mainly urban dwellers. However the prevalence of late booking is higher than a study conducted in Kassala (Eastern Sudan) and similar to a study conducted in Durban, South Africa $[16,17]$.

After controlling the effect of other variables rural residence, no formal education, lower household income, not being advised and unplanned pregnancy were significantly associated with late presentation for first ANC visit. Rural women were 3.6 times more likely to be booked late for their first ANC visit than urban dweller women. This finding is supported by a study conducted in Hadiya, SNNP in which late ANC service utilization is two times higher in rural than urban residents [18]. This could be due to the fact that urban residents are nearer to health facilities, are educated and knowledgeable. Furthermore illiterate women were 1.48 more likely to be late for ANC visit than women who have formal education. It is also in line with other studies $[16,18]$.

Similarly pregnant women who had low household monthly income were 3.2 times more likely to be booked late for their first ANC booking as compared to their counterparts with high monthly income. This finding is in line with a study conducted in Hadiya Zone (Ethiopia), Holeta town (Ethiopia), and Nigeria [12,15,18]. This could be because of the fact that those who have better income are more educated and income increase the ability to pay for health care services, transportation, and other indirect costs.

The other factor that significantly associated with late antenatal care entry in this study was not getting advice about timing of first ANC. 
Citation: Girum T (2016) Assessment of Timing of First Antenatal Care Visit and Associated Factors Among Pregnant Women Attending Antenatal Care in Dilla Town Governmental Health Institutions, Southern Ethiopia. Altern Integr Med 5: 220. doi: $10.4172 / 2327-5162.1000220$

Page 5 of 5

This study found that pregnant women who did not receive advice on recommended time were 4.64 times more likely to be registered late for their first ANC as compared mothers who ever received an advice. This was in line with studies conducted in Addis Ababa and Uganda, in which women were more likely to visit earlier when they were advised up on their pregnancies [13,19]. Accordingly having unplanned pregnancy was found to be a significantly associated with late booking of ANC. In this study it was found that women with unplanned pregnancy were 5 times more likely visit late for their first ANC as compared to their counterparts. This finding is in line with studies conducted in south west Nigeria and Kenya $[14,15]$.

Even though this study has come up with important finding with respect to late registration for first ANC visit, there are certain limitations worth mentioning here. Due to cross- sectional nature of the study temporal relationship could not be ascertained. The other concern was pregnant women who attend antenatal care at private health facilities are not included in the study. Moreover, gestational age was determined based on women's reports of their last menstrual period (LMNP). However, it can be applicable to similar population.

\section{Conclusion and Recommendation}

The study showed that nearly half of women initiated their first ANC booking later than the recommended time and the mean time for the record was 15.9 (SD 3.7) weeks. Being rural resident, having lower monthly income, not received advice on when to start antenatal care visits, No formal education and unplanned pregnancy were factors significantly associated with late first antenatal care booking. Therefore addressing rural women through health extension workers, giving an advice, improving economic capacity and avoiding unplanned pregnancy through family planning are important measures to overcome the problem.

\section{Acknowledgments}

I would like to sincerely thank Head of the health institutions, data collectors and study participants.

\section{References}

1. WHO (2014) Trends in Maternal mortality 1990-2013, Estimates by WHO, UNICEF, UNFPA, the World Bank, and the United Nations Population Division, World Health Organization, Geneva, Switzerland.

2. Hogan MC, Foreman KJ, Naghavi M (2010) Maternal mortality for 181 countries, 1980-2008: a systematic analysis of progress towards millennium development goal 5. The Lancet 375: 1609-1623.
3. Hill K, Thomas K, Zahr CA, Walker N, Say L, et al. (2007) Estimates of maternal mortality worldwide between 1990 and 2005. The Lancet 370: 1311-1319.

4. Central Statistical Agency (2014) Mini Ethiopia Demographic and Health Survey 2014, Central Statistical Agency, Addis Ababa, Ethiopia.

5. Villar J, Bergsj P (2002) Manual for the implementation of new model, WHO Antenatal Care Randomized Trial, World Health Organization. Geneva.

6. Carroli G, Rooney C, Villar J (2001) How effective is antenatal care in preventing maternal mortality and serious morbidity? An overview of the evidence. Paediatr Perinat Epidemiol 15: 1-42.

7. WHO (2005) The World Health Report 2005: Make Every Mother and Child Count, World Health Organization, Geneva, Switzerland.

8. Central Statistical Agency [Ethiopia] and ICF International (2012) Ethiopia Demographic and Health Survey 2011. Addis Ababa, Ethiopia and Calverton, Maryland, USA.

9. Wado YD, Afework MF, Hindin MJ (2013) Unintended pregnancies and the use of maternal health services in S.W. Ethiopia. BMC Int Health Hum Rights 13: 36.

10. Simkhada B, Teijlingen ER, Porter M, Simkhada P (2008) Factors affecting the utilization of antenatal care in developing countries: systematic review of the literature. J Adv Nurs 61: 2440-260.

11. Tsegay Y, Gebrehiwot T, Goicolea I, Edin K, Lemma H, et al. (2013) Determinants of antenatal and delivery care utilization in Tigray region, Ethiopia: a cross-sectional study. Int J Equity Health 12: 30.

12. Birmeta K, Dibaba Y, Woldeyohannes D (2013) Determinants of maternal health care utilization in Holeta town, central Ethiopia. BMC Health Services Research 13: 256

13. Tariku A, Melkamu Y, Kebede Z (2010) Previous utilization of service does not improve timely booking in antenatal care: Cross sectional study on timing of antenatal care booking at public health facilities in Addis Ababa. Ethiop. J Health Dev 3: 226-33.

14. Anna E, Hanneke M, Frank O (2006) Use of antenatal services and delivery care among women in rural western Kenya: a community based survey. Reprod Health 3: 2 .

15. Adekanle D, Isawumi A (2008) Late antenatal care booking and Its predictors among pregnant women In South Western Nigeria. Online J Health Allied Sci 7: 4 .

16. Abdel AA, Mohammed O, Ameer A (2010) Use of antenatal care services in Kassala, eastern Sudan. BMC Pregnancy Childbirth 10:3.

17. Sibeko S, MBCh B (2006) Healthcare attendance patterns by pregnant women in Durban, South Africa. SA Fam Pract 48: 17.

18. Zeine A, Mirkuzie W, Shimeles O (2010) Facors influencing antenatal care service utlization in Hadya zone Ethiopia. J Health Sci 20: 75-82.

19. Lynn A, Florence M, Nazarius M (2008) Adolescent and adult first time mothers' health seeking practices during pregnancy and early motherhood in Wakiso district, central Uganda. Reprod Health 5: 13. 